\title{
Acute Appendicitis: Standard Treatment and the Role of Laparoscopic Surgery
}

\author{
M. Schäfer, L. Krähenbïhl, M. Schneider, and M.W. Büchler
}

\author{
Key-words: Laparoscopy - acute appendicitis - appendectomy - \\ laparoscopic appendectomy.
}

\section{Introduction}

Appendicitis remains a frequent disease with an overall incidence of 110 to 250 per 100,000 per year in western countries. Patients of all ages may develop acute appendicitis and need immediate treatment, which is usually an emergency operation to remove the inflamed appendix. Various symptoms can occur, and therefore. the clinical presentation of acute appendicitis varies greatly. Thus, the diagnosis is still challenging and even experienced surgeons may fail. Despite technical advances and the availability of newer diagnostic tools (laboratory parameters, ultrasound. CT-scan) the clinical findings and the patients' history remain important for the diagnosis of and the decision-making for acute appendicitis. Neither the perforation nor the negative appendectomy rates have substantially changed over the last 70 years. However, the overall mortality rate has significantly decreased over this time.

Since the famous description of McBurney in 1894, the surgical technique of open appendectomy has not changed. The muscle-splitting approach in the right iliac fossa represents the gold standard for operative treatment. This procedure is quick and easy to perform, and is also associated with a low morbidity and mortality. Finally. it represents a typical minor operation often performed by surgical residents.

The successful introduction of minimal invasive surgery has markedly influenced the development of general surgery over the last 10 years. In particular, laparoscopic cholecystectomy has fully replaced the former open procedure and it is now considered to be the new standard treatment of symptomatic gallstone disease (1). However. laparoscopic appendectomy has never become popular, although Senm had already described it in 1983 (2). Perhaps the most fundamental reason is skepticism about its ability to improve upon the open procedure. The muscle-splitting approach is already a "minimal invasive procedure" and therefore. laparoscopy may not have any further advantages.

The aim of our fourth international meeting on laparoscopic surgery was to review the diagnostic and therapeutic approaches to acute appendicitis and to define the current state of treatment Following an epidemiological and pathogenetic background and discussion on the diagnosis of and decision-making for acute appendicitis, traditional open and laparoscopic procedures were presented and discussed. Finaly, the international resulss of oper versus laparoscopic appendectomy were compared.

\section{Appendicitis: Pathogenetic Backgrom}

$U$. Boschung, Bern, presented the historical background of "Right Mlac Fossa Pain". The first descriptions of "the appendix vermiformis" were published in Europe by Italian anatomists in 1521 and by Verheyen in 1710 (3). Reginald Heber Fitz (Bo-

Corresponding address: M. W. Büchler, M.D., Department of Visceral and Transplantation Surgery, University of Bern, Inselspital. CH-3010 Bern, Switzerland. ston, 1886) was the first to describe the symptoms of early acute appendicitis and he proposed a two-staged procedure for its treatment (4). If the conservative treatment had failed after 1 to 2 days, he proposed the removal of the appendix as the ultima ratio to save the patient's life. Claudius Aymond performed the first successful appendectomy at St. George's Hospital in London in 1735.

In Switzerland, both Charles Krafft and Theodor Kocher (former chairman of the surgical department of the University of Bern and winner of the Nobel prize) proposed an early operation for the successful treatment of acute appendicitis in 1888 and 1892. Only some years later (1913), Fritz de Quervain (successor of Kocher as chairman of the surgical department) presented the first metaanalysis of the available data and proved the reduction in mortality after early operative removal of an inflamed appendix.

Ch. Maurer, Bern, presented the epidemiology, etiology and pathogenesis of acute appendicitis. The overall incidence of appendicitis is estimated to be 110 per 100,000 per year in western countries. Children and adolescents have a much higher incidence, which reaches 230 per 100,000 per year. There is some variation in the incidence, e.g. whites and men have a higher incidence than non-whites and women. Furthermore, acute appendicitis is more frequent in summer than in winter, and there is a positive familial correlation.

The clinical course of acute appendicitis, especially the perforation rate, is age dependent and affects more individuals at the extremes of age. This is probably due to delayed diagnosis.

The most common etiological factors are faecoliths, local hyperplasia of the lymphoid tissue, septa with mucus retention, low fiber diet, foreign bodies and neoplastic lesions. Obstruction of the appendiceal lumen is thought to be the relevant pathogenetic mechanism which leads to the development of acute appendicitis.

A. Zimmermann, Bern, presented the histopathology and classification of appendicitis. According to histopathological and pathogenetic criteria there is large range of different types of appendicitis. It may be related to inflammatory bowel disease, to vascular and collagen disorders or to other specific infections. Furthermore, idiopathic granulomatous or eosinophilic or neurogenic appendicitis has been recognized. But the impact of such an exensive classification remains of minor importance in daily clirical work.

More important is the time course of acute appendicitis. Within a few hours of clinical onset, a localized epithelial lesion with infiltration of white blood cells is noted. Formation of ulcers with extensive infiltration of granulocytes can be observed after 10 to 14 hours. 24 hours after the onset of the epithelial lesion, deep ulcers with transmural defects are fully established, frequently accompanied by a local peritonitis. Perforation only occurs if ischemic lesions are present.

P. Di Sebastiano, Pescara, presented the role of nerves in pain generation of acute appendicitis. Although up to $20 \%$ of all ap- 
pendices removed for suspected appendicitis show no histological signs of acute inflammation, these patients have been suffering from right iliac fossa (RIF) pain. Therefore, the mechanism of pain generation in acute appendicitis remains unclear. From experimental work, it is known that local irritation of nerves or nerve growth can cause RIF pain. Histological examinations using special staining methods for visualizing nerves have revealed a very close contact between nerve fibers and lymphoid tissue in the appendix. Thus, a humeral interaction may be responsible for the pain generation. This hypothesis is also supported by the fact that increased local concentrations of VIP and SP in non-inflamed appendices were demonstrable (5).

A. Telenti, Bern, presented the bacteriology and the role of antibiotics in acute appendicitis. Various species of bacteria can be found in acute appendicitis, mostly representing normal stool flora. Perioperative antibiotics for uncomplicated appendicitis (without perforation) decrease the wound infection rate. Furthermore, the systematic application of perioperative antibiotics is indicated because of the poor correlation between the intraoperative macroscopic aspect and the postoperative microscopic findings. The available data on the optimal treatment of perforated appendicitis with or without peritonitis are confusing and different regimens have been proposed. Summarizing the data, he proposed the following regimen. Single-shot antibiotic prophylaxis for all patients with suspected appendicitis undergoing (open or laparoscopic) appendectomy. The treatment should be prolonged for 3 to 5 days or even 5 to 10 days with a broad spectrum antibiotic for perforated appendicitis and peritonitis, respectively.

H. Säuberli, Baden, presented the clinical picture and differential diagnosis of appendicitis and RIF. The diagnosis of and the decision-making for acute appendicitis still remain clinically based without the help of ultrasound or laparoscopy. Radiological examinations and laboratory findings are only additional tools, which may give further information. Generally, an acute appendicitis can mimic many other intraabdominal diseases. Often, the most reliable symptom is the pain and its time course, which show a typical pattern in about $55 \%$ of the patients. The remaining $45 \%$ of patients have an atypical pattern with "non-typical" pain. The "typical" pain starts in the epigastrium and then moves to the right iliac fossa within 24 hours. Nausea and loss of appetite are the second most frequent symptoms. Especially children and elderly patients do not show the typical signs of acute appendicitis and therefore, a high perforation rate is found in these 2 patient groups due to delayed diagnosis. Acute appendicitis during pregnancy is the most common extrauterine reason for an operation. Furthermore, the appendix moves cranially during pregnancy.

\section{Diagnosis, Decision-Making and Standard Surgery}

W. Schwerk, Kiel, presented the imaging and the specific role of ultrasound in appendicitis. The diagnosis of acute appendicitis remains difficult, mostly due to the unspecific symptoms. Especially in young women, the reported negative appendectomy rate is 25 to $48 \%$. Furthermore, the decision must be taken under time pressure and often without the availability of any imaging technique. Ulirasound has become very popular and is now available in many hospitals. It is a non-invasive and cheap imaging technique, which can be done by radiologists and surgeons. The typical ultrasonographic findings are an incompressible appendix, visualization of the different layers of the appendiceal wall on a cross-section and increased vascularization of the appendix. Schwerk presented the results of his own study, which was published $1990(6)$, where they found a sensitivity of $90 \%$ and a specificity of $98 \%$. The negative and positive predictive values were $94 \%$ and $97 \%$, respectively. The overall accuracy was $96 \%$. Finally, they were able to decrease the negative appendectomy rate from $20.3 \%$ to $11.3 \%$. The lymphadenitis mesenterica and the ileitis terminalis, which represent the two most important diffe- rential diagnoses, can be excluded in almost all cases. He summarized that with the use of ultrasound, a better preoperative diagnosis and differential diagnosis is possible, the negative appendectomy rate is decreased and the detection rate of perforated appendicitis is increased.

C. Ohmann, Düsseldorf, presented the decision-making for acute appendicitis. Anamnestic, clinical and laboratory findings are the basic factors determining the decision-making for acute appendicitis. According to these basic factors, three possibilities for RIF pain can be distinguished. "Obvious" cases with a high suspicion of acute appendicitis should be operated without any further investigations or delay. Patients with "unclear" RIF pain, who may have an acute appendicitis, should be clinically observed and further investigated by ultrasound. If an acute appendicitis is very unlikely and any other relevant diagnosis can be made. the patient should be discharged. The author proposed a scoring system as a diagnostic tool to better a patient's evaluation, which was published in 1995 (7).

S. Paterson-Brown, Edinburgh, presented the early versus delayed treatment of acute appendicitis. The diagnosis of acute appendicitis remains difficult, which is represented by the high rate of negative appendectomies. Nevertheless, the overall mortality is low $(0.24 \%)$. The duration of symptoms partly correlates with the perforation rate. On the other hand, there is strong evidence that some patients have chronic or recurrent appendicitis. which represent two other, different entities of appendicitis. He, therefore, proposed an early operation for acute appendicitis, not only to remove the inflamed appendix, but also to find another pathology which could possibly have caused the RIF pain. In cases of recurrent appendicitis, at least $6.5 \%$ of patients will have two episodes of RIF pain which can be prevented if the appendix is removed during the first onset. Finally, although a non-operative treatment with only antibiotics may be feasible, it has a high recurrence rate at long-term follow-up.

Ch. Seiler, Bern, presented the standard open surgical treatment for appendicitis. McBurney described the standard technique of open appendectomy in 1889 (8). Over a century, this technique has not changed and it still represents the gold standard, although many technical variants of the initial procedure have been described. The oblique skin incision is made in the lateral third of a line joining the umbilicus and the anterior superior iliac spine in the RIF. The subcutaneous fat is divided and the underlying muscle layers are split bluntly. Finally, the peritoneum is opened and the cecum, together with the appendix, can be easily mobilized. The mesoappendix is divided using clamps and ligatures, followed by ligation of the appendix itself. After removal of the appendix, the stump is normally buried in the cecal wall using a purse string or Z-stitch. The abdominal wall is then closed in layers with absorbable sutures. The peritoneum is first closed with a running suture, followed by readaptation of the muscles with interrupted sutures and closure of the skin incision.

$P$. Vogelbach, Basel, presented the complications of open appendectomy. Although the mortality is very low, the reported complication rates of open appendectomy vary trom 5 to $15 \%$. Perforated appendicitis shows a significantly increased complication rate compared to non-perforated appendicitis. Wound infections are the most common complications and occur in 7 to $10 \%$, followed by intrabdominal abscess formation (4\%). The exact amount of adhesion formation is difficult to evaluate, but late postoperative bowel obstruction occurs in 1 to $2 \%$. The overall complication rate after laparoscopic appendectomy is almost equal to the rate for open appendectomy found in most of the randomized trials. However, laparoscopic appendectomy has a significantly decreased wound infection rate.

P. Puri, Dublin, presented the rate of negative appendectomy: Is it really negative? Appendices removed from children 
with suspected appendicitis often appear normal on routine histological examination. But focal appendicitis has been demonstrated in histologically normal appendices from patients with a clinical diagnosis of acute appendicitis. Cytokine concentrations (several types of interleukin, tumor necrosis factor) are raised in focal appendicitis and can be visualized with immunochemical methods. He performed a study measuring interleukin 2 (IL-2) and tumor necrosis factor (TNF-alpha) in normal appendix, acute appendicitis and so-called histologically normal appendix. $22 \%$ of the histologically normal appendices showed an increased concentration of IL-2 and TNF-alpha, which was similar to those of the histologically proven acute appendicitis. Thus, a substantial proportion of histologically normal appendices had clear evidence of an inflammatory response. His conclusion was that the reported negative appendectomy rates are probably too high (9).

\section{Laparoscopic Treatment of Acute Appendicitis}

L. Krähenbiihl, Bern, presented the standard laparoscopic technique in adults. Although Semm described laparoscopic appendectomy in 1983, only between $1 \%$ and $10 \%$ of all appendectomies are performed laparoscopically. The indications for laparoscopic appendectomy are acute appendicitis, suspicion of acute appendicitis, chronic appendicitis and RIF pain in young females. The contraindications for laparoscopic appendectomy are inflammation of the cecum or perforation at the base of the appendix, appendiceal cancer and the patient's condition. No standard technique has been described, however, in Switzerland laparoscopic appendectomy is performed using single-shot antibiotics and selective bladder and stomach decompression. A three trocar technique $(5,10$ and $12 \mathrm{~mm})$ where the first trocar is inserted openly (Hasson technique) is preferred. Dissection of the mesoappendix is performed with bipolar current and the base of the appendix transected with a stapling device. The appendix is either removed through the $12 \mathrm{~mm}$ trocar or with help of a bag. No drainage is inserted.

C. Muiller, Genf, presented the standard laparoscopic technique in children. About 5000 laparoscopic appendectomies have been performed in children. Children's anatomical site and physiology varies greatly from adults. Standard instruments are often too large and may increase the risk of iatrogenic injuries of intraabdominal organs. Furthermore, only a low $\mathrm{CO}_{2}$-pressure and limited Trendelenburg position can be used to avoid respiratory aspiration because general anesthesia is usually performed with uncuffed tubes. Since its introduction, no standard pediatric technique has been established and no results of prospective randomized trials are available. Therefore, no proven benefits have been described. Better diagnostic possibilities, especially for girls with unclear RIF pain, and probably a better cosmetic result are the major advantages. Assisted laparoscopic appendectomy with a single trocar technique is used as well as appendectomy performed completely intraabdominally (with 3 trocars). Increased intracerebral pressure, congenital cardiac malformations, congenital dysplasia of the lungs and hematological disorders are the main contraindications for performing laparoscopic appendectomy in children.

Ph. Morel, Genf, presented the dangers and compineations of laparoscopic appendectomies. The introduction of a new technique usually causes new types of complications. Perforation of the great vessels or bowel injuries from Veress needles are rare (0.02 to $0.9 \%$ ) but serious complications of laparoscopy. Thus, using the open or Hasson technique for establishing the pneumoperitoneum has markedly decreased these complications. The increased intraabdominal pressure of the pneumoperitoneum is another well described factor which leads to gastro-esophageal reflux, aspiration, decreased cardiac output, pneumothorax and gas embolism (incidence 0.02 to $0.06 \%$ ). Thermal injuries can occur using monopolar current or from the light source. Trocar hernias mainly occurred at the introduction of laparoscopy, but today, trocar sites ( $>10 \mathrm{~mm}$ ) are routinely closed by suturing the abdominal wall defect in layers.

Technical failure to remove the appendix leads to re-inflammation of the residual appendiceal stump or abscess formation.

E. Neugebauer, Köln, presented a metaanalysis of studies comparing open versus laparoscopic appendectomy. Since its introduction in 1983, 21 randomized trials have been performed comparing open and laparoscopic appendectomy. A metaanalysis is a structured approach for integrating the results of different studies in a qualitative and quantitative manner in order to overcome the disadvantages of traditional review articles. The main outcomes were operating time, complication rate, postoperative hospital stay, postoperative pain, first bowel movement, return to normal activities and work, as well as costs.

The mean operating time varied greatly, but all studies reported longer operating time for laparoscopic appendectomy. However, a learning curve bias was found in at least half of the studies, and the impact of 10 or 15 min of operating time is up to clinical interpretations. A "true" complication rate could not be defined due to heterogenous definitions of the term "complication". Nevertheless, the reported rate of infectious complications after laparoscopic appendectomy was generally lower than after open appendectomy. The length of hospital stay and return to work were markedly influenced by the medical staff treating the patients and the national health care system. Therefore laparoscopic appendectomy showed no advantages. Postoperative pain was reduced after laparoscopic appendectomy, but the methodological approach to measuring pain varied, therefore it was impossible to combine the results and to conclude any hard facts. Costs were estimated in just a few studies. All of them found higher direct costs for laparoscopic appendectomy; however, a thorough economic analysis has not yet been performed.

A. Pier, Bedburg, presented the argaments for laparoscopic appendectomy. Although the learning curve and the absence of a standard technique may still bias the results of laparoscopic appendectomy, Pier emphasized the major advantages of laparoscopic appendectomy. Diagnostic evaluation of the abdominal cavity is easier to perform using laparoscopy. Young females with unclear RIF pain benefit particularly from this diagnostic tool because gynecological disorders can often be excluded. At least some studies revealed less postoperative pain, decreased hospital stay and earlier return to work. Furthermore, cosmesis is often more advantageous after laparoscopic appendectomy. It is also thought that laparoscopic appendectomy causes less adhesion formation due to its minimally invasive approach.

J. J. T. Tate, Bath, presented the arguments against laparoscopic appendectomy. Operating time is significantly longer for laparoscopic compared to open appendectomy. The wide use of non-disposable instruments causes higher direct costs. Laparoscopy needs expensive and susceptible technical equipment. Laparoscopic appendectomy requires additional surgical skills, and consultants often perform the operation. In fact standardized training programs for laparoscopic surgery are non-existent in many countries.

\section{W. Intemational Results of Open versus Iaparoscopic} Appendectomy

The results of laparoscopic appendectomy from France (A. Fingerhut), Germany (U. Hildebrandt), Austria (W. Waynand), the Netherlands ( $H . J$. Bonjer), Switzerland (E. Frei). US. (N.J. Soper), Great Britain (A. Darsi) and Australia (G. Maddern) were presented.

In most of these countries prospective randomized trials or at least large series of laparoscopic appendectomies have been performed, and therefore an extensive body of experience was presented. Acute appendicitis was the most frequent indication for appendectomy. Laparoscopic appendectomy was performed using a 3-trocar technique. After bipolar coagulation of the mesoappen- 
dix, the division of the appendix was performed using endo-loops or a stapling device. The reported conversion rates were 2 to $20 \%$, and conversion was mostly performed due to a heavily inflamed or even perforated appendicitis with peritonitis. The operating time was longer compared to open appendectomy. However, postoperative pain, length of hospital stay, off work time, overall morbidity and mortality showed no difference. The wound infection rate was significantly reduced after laparoscopic appendectomy. Presumably, this can be explained by a better wound protection because removal of the appendix was normally performed through a trocar.

However, in all these countries, laparoscopic appendectomy has never become the standard treatment for acute appendicitis. Laparoscopic appendectomy as a standard treatment is often restricted to a few surgical institutions. Only between $1 \%$ and $11 \%$ of all appendectomies have been performed laparoscopically and the individual experience of the surgeons is quite limited. The reasons for this surprisingly low rate of laparoscopic appendectomies are unknown. The higher costs, the longer operating time and the increased technical expenditures as well as the inconspicuous existing advantages may play a role.

\section{Conclusion}

M.W. Büchler, Bern. Acute Appendicitis: The Role of Laparoscopic Surgery. The conclusion at the end of the meeting by $M$. W. Buichler, Bern, was that the standard treatment for acute appendicitis remains the classic open technique described by McBurney in 1894. Only between 1\% (United Kingdom) and $20 \%$ (USA) of all cases are removed laparoscopically. However,
$12 \%$ of all surgical cases are performed for appendicitis and $40 \%$ of all small bowel obstructions are related to open appendectomy. The metaanalysis comparing laparoscopic versus open appendectomy showed that laparoscopic appendectomy is more expensive and takes longer. the complication rates are equal and there are no differences concerning pain, recovery and cosmesis. Despite the fact that laparoscopic appendectomy is a safe procedure, open appendectomy remains the standard procedure for clear diagnosis. However, the role of laparoscopic appendectomy in young females, obese patients and unclear diagnosis must be further evaluated.

\section{References}

(1) Büchler MW. Frei E. Klaiber Ch. Krähenbühl L (eds): Five years of laparoscopic cholecystectomy: a reappraisal. Progress in Surgery. Vol 22. Basel, Karger, 1996. (2) Semm K: Endoscopic appendectomy. Endoscopy 1983:15:59-64.

(3) Herrington JL: The vermiform appendix: Its surgical history. Contemp Surg 1991;39:36-44.

(4) Fitz RH: Perforating inflammation of the vermiform appendix: With special reference to its early diagnosis and treatment. Am J Med Sci 1886:92:321-346.

(5) Di Sebastiano P. Fink T. Weihe E. Friess H, Beger HG, Büchler MW: Changes of protein gene product 9.5 (PGP 9.5) immunoreactive nerves in inflamed appendix. Dig Dis Sci 1995;40:366-372.

(6) Schwerk W. et al: Acute and perforated appendicitis: current experience with uitrusound-aided diagnosis. World J Surg 1990:14:271-276

(7) Ohmann C. et al: Diagnostic score for acute appendicitis. Chirurg 1995:66:360365

(8) McBurney C: Experience with early operative interference in cases of disease of the vermiform appendix. N Y State Med J 1889:50:676.

(9) Wang Y. Reen DJ. Puri P: Is a histological normal appendix following emergency appendicectomy always normal? Lancet 1996:347:1076-1079.

(10) Krähenbühl L. Metzger A, Büchler MW: Five Years of Laparoscopic Cholecystectomy: A Reappraisal (Congress Summary). Acta Chir Austriaca 1995:27:226-231.

\section{Ultraschall Lexikon}

1996. XI, 158 Seiten mit 120 Abbildungen, davon 40 farbig. $17 \times 24 \mathrm{~cm}$. Broschiert. DM 48,-/ÖS 350,-/sFr 44,50 ISBN 3-89412-234-X

Die Anwendung des Ultraschalls zu diagnostischen und therapeutischen Zwecken ist zum zentralen bildgeben-

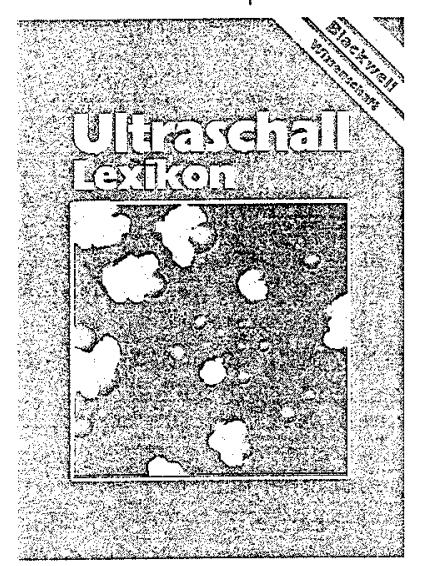

den Verfahren in den meisten klinischen Fachdisziplinen geworden und hat viele konventionelle Untersuchungsmethoden abgelöst. Mit rund $\mathbf{8 5 0}$ Stichworteinträgen gibt das Lexikon fachübergreifend sachkundig Antwort auf alle wichtigen klinischen und technischen Fragestellungen zu dieser Thematik.

Enthalten sind Begriffe von A-Bild bis Mitralklappeninsuffizienz und Belastungsechokardiographie, 3-D-Rekonstruktion, Doppler-shift, FourierAnalyse, Grauwertskala sowie von Lebermetastasen über Gallenblasenhydrops bis Lymphknoten, von Schwangerschaft bis Flowmessung in der $A$. umbilicalis und Uterus myomatosus sowie von Muskel bis Achillessehne und von Hydrozele bis Nierensteine - um nur einige Beispiele zu nennen. Die Stichwörter wurden aus allen Anwendungsgebieten des Ultraschalls zusammengeführt und sind in knapper, übersichtlicher Form definiert.

Zur Veranschaulichung der Diagnostik sind klassische Befunde durch über 100 Grafiken und Abbildungen dokumentiert, davon viele Farbabbildungen, die in einem speziellen Farbtafelanhang $u$. a. die neuesten technischen Möglichkeiten der Ultraschalldiagnostik, wie Pulsdoppler und Signalverstärkereinsatz, darstellen. Tabellen ermöglichen eine schnelle Abgrenzung der unterschiedlichen Befundkriterien und Krankheitsbilder. Darüber hinaus kann sich der Benutzer durch zahlreiche Verweise innerhalb der Stichworttexte auf zeitsparende und effektive Weise zusätzliche bzw. weiterführende Informationen erschließen.

\section{Blackwell Wissemscharts-Verlag Bermin. Men}

